\title{
Creation of modified friction surfaces
}

\author{
Andrei Gorin ${ }^{1}$, Alexandr Novikov ${ }^{1}$, Svetlana Karpeeva ${ }^{1}$ and Maria Tokmakova ${ }^{1}$ \\ ${ }^{1}$ Orel State University named after I.S. Turgenev, Komsomolskaya st. 95, 302026, Orel, Russia
}

\begin{abstract}
The article provides information on the creation of modified friction surfaces. The results of the analysis of the applied antifriction film coatings are presented. One of the main problems in the application of thin film coatings is the lack of technological modes recommended by the manufacturer. The composition of the film anti-friction coating is described. The results of experimental studies of the deposition of thin film coatings are presented. Selected pneumatic spray gun for depositing of thin film coating. A series of experiments were carried out to identify the technological modes of applying thin film coatings. A qualitative and quantitative analysis of the results of applying thin film coatings has been carried out. A functional diagram of the application of an antifriction film coating is proposed. On the basis of the conclusions made, recommendations are given on the technological modes of applying thin film antifriction coatings on the modified friction surface.
\end{abstract}

\section{Introduction}

One of the main selection criteria when buying a unit or a vehicle is its reliability, which consists of durability, maintainability and preservation. Recently, in units and mechanisms, modified friction surfaces are often used, which are parts with various types of coatings. Such surfaces increase reliability and the service life of parts and mechanisms [1,2]. Wherein, such parts are very often multi-layer products, consisting of a steel base with subsequent coating on it. The properties of the coating depend on the material and how it is applied. It must be taken into account that the properties of the applied coating must fully comply with the operating conditions of this part [3,4]. The coatings used in the maintenance and repair of machines, according to their purpose, are usually subdivided into the following main groups: wear-resistant, paint and varnish, antifriction, corrosionresistant, heat-resistant. In most cases, the coating changes the overall and mounting dimensions. The dimensions of the parts increase by the thickness of the applied coating layer. In many cases, this is unacceptable, as it leads to a change in the technical parameters of units and parts. $[5,6]$.

This problem can be solved by the use of new materials, in particular, film coatings (the thickness of the film layer is from 5 microns to 30 microns), which can significantly increase the performance of machine parts.

\footnotetext{
* Corresponding author: gorin57@mail.ru
} 


\section{Problem formulation}

Various film coatings have been used in manufacturing, maintenance and repair in recent years. At the moment there is a huge range of film coatings. They can be divided according to the method of application, composition, properties, purpose, etc. An important factor is the price of this type of coating. The consumer finds himself in a difficult situation when choosing what he needs. The main problem is that it is necessary to choose a coating that will perform its functions, be easily applied to the surface of the product, without requiring complex devices and equipment, and at the same time have a high adhesive strength of adhesion to the base metal $[7,8,9]$. Usually the manufacturer does not describe the coating process. The documents attached to the coatings do not indicate the main modes that affect the tribological properties of the formed film coatings [10,11,12].

\section{Theoretical part}

Film anti-friction coatings, after forming on friction surfaces, are firm to the touch, in appearance they are similar to paint coatings. Anti-friction film coatings contain solid lubricants as pigments, resins as a binder, and a solvent liquid [13]. Molybdenum disulfide, graphite and PTFE are mainly used as pigments. The composition of the film anti-friction coating is presented in the form of a diagram - Fig. 1.

The fundamental factor for ensuring the lubricity of the coating during operation, in addition to the selection of the individual component, is also the volume concentration of pigments in the coating composition. Film anti-friction coatings are applied mainly by spraying, on previously degreased surfaces, it is also possible to apply by tumbling, immersion in a centrifuge, electrostatic and automatic spraying, printing, rolling followed by drying at room temperature or in an oven [14].

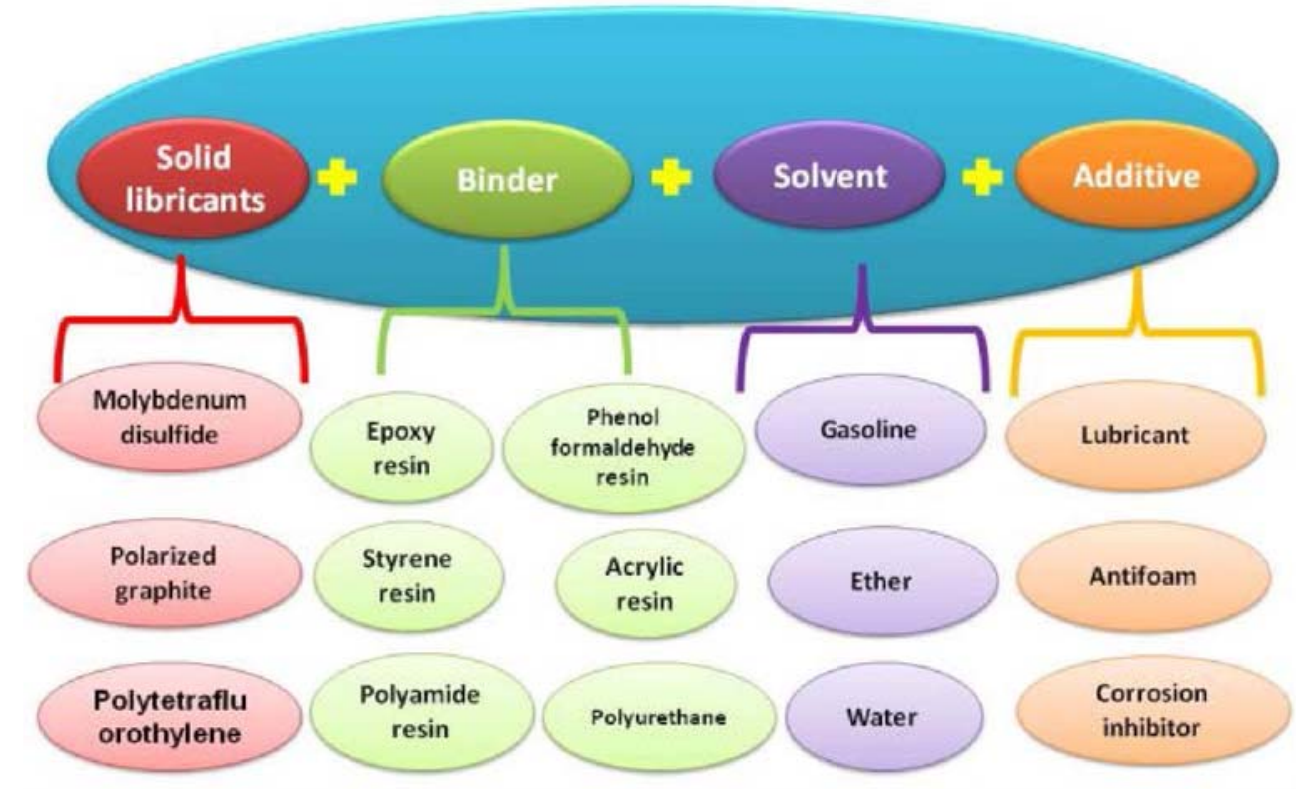

Fig. 1. The composition of the film anti-friction coating.

The universal tool for applying film anti-friction coatings is a pneumatic spray gun. This type of coating is the simplest and most affordable. The work of this tool consists in the fact that the antifriction material supplied to the spray gun and exiting its nozzle is 
splitting into small particles by a stream of compressed air, "shooting" at high speed from the holes of the air cap. As a result, a so-called "torch" is formed, consisting of particles of material moving towards the workpiece or surface. Having reached the surface, the particles settle on it, forming a coating [15]. The quality of application of this coating will be largely influenced by the process of formation of the "torch", which in turn will depend on the distance of the pneumatic spray gun to the part and the speed of the outgoing air flow.

The quality of the applied coating depends on many factors. One of the main indicators of the quality of the coating is the adhesion strength of the film coating (adhesion) to the base, which is determined by the relationship:

$$
Y=f(L, \alpha, C, R a, t, \rho, v, d, D),
$$

where $L$ - coating distance, $\mathrm{mm}$;

$\alpha$ - angle of coating, degrees;

$C$ - method of surface preparation;

$R a$ - surface roughness, microns;

$t$ - ambient temperature, ${ }^{\circ} \mathrm{C}$;

$\rho$ - density of the applied coating, $\mathrm{g} / \mathrm{l}$;

$v$ - humidity of the environment, $\%$;

$d$ - diameter of the diffuser of the atomizer, $\mathrm{mm}$;

$D$ - pressure in the air line, MPa.

Various scientists have been involved in research in this area. According to the studies [16] (Figure 1), the maximum adhesion strength of the antifriction film coating to the base occurs at a spraying distance $L=180 \ldots 200 \mathrm{~mm}$ and a coating angle $\alpha=90^{\circ}$.

Of all the factors listed above, special attention should be paid to the settings of the pneumatic spray gun. The settings of the pneumatic nozzle affect the process of forming a "torch", which in turn will depend on the distance of the pneumatic nozzle to the part L and the speed $\mathrm{V}$ of the outlet air flow. If we take all other factors equal to a constant value, then for this case, the quality of the applied coating is determined by the relationship:

$$
Y=f(L, V),
$$

where $L$ - coating distance, $\mathrm{mm}$;

$V$ - air flow speed, deg.

Three tests are known to assess the correct operation of the pneumatic spray gun and the correctness of its adjustments:

- test of the correct shape of the torch print;

- test for uniformity of coating distribution in the torch;

- spray quality test.

\section{Experimental studies}

As practice shows, the highest coating efficiency when using a pneumatic atomizer is achieved when working with a torch of the maximum size. The wider and more uniform the torch, the more evenly the coating will be distributed over the surface with fewer passes. The situation is quite different when coating in special or individual hard-to-reach places and on small parts. It is necessary to take into account the qualifications and experience of personnel working on technological equipment for the application of film anti-friction coatings. The process of coating the inner and outer surfaces of bodies of revolution deserves special attention. it becomes necessary to take into account additional factors 
ensuring the quality of the coating. When coating unique small parts, torch shape, paint flow and inlet pressure can be adjusted as needed.

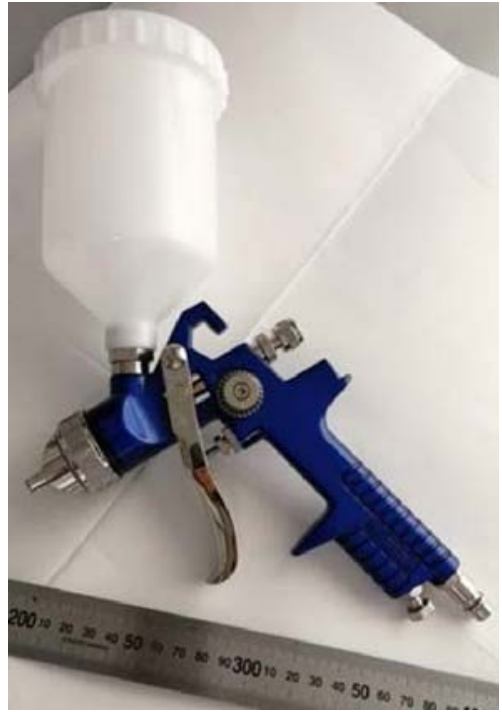

a)

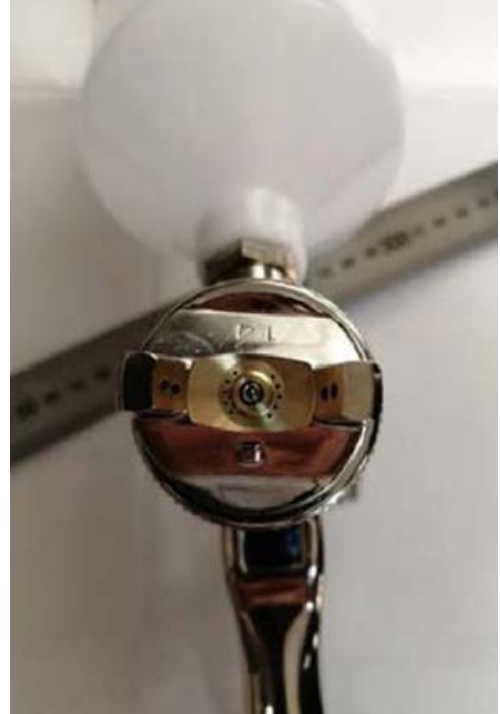

b)

Fig. 2. Pneumatic spray gun for coating. (a) side view; (b) front view.

To determine the effect of distance and speed on the quality of the applied coating, a field experiment was carried out. The objective of the experiment was to obtain the optimal values of air velocity and coating application distance to obtain a high-quality coating with its maximum transfer. For the experiment, a spray gun Constanta A was prepared. (Fig. $2 \mathrm{a}, \mathrm{b})$. Film antifriction coating based on molybdenum disulfide (12\%) with an organic binder, curing at normal temperature (Fig. 3a) and aerometer (Fig. 3b).

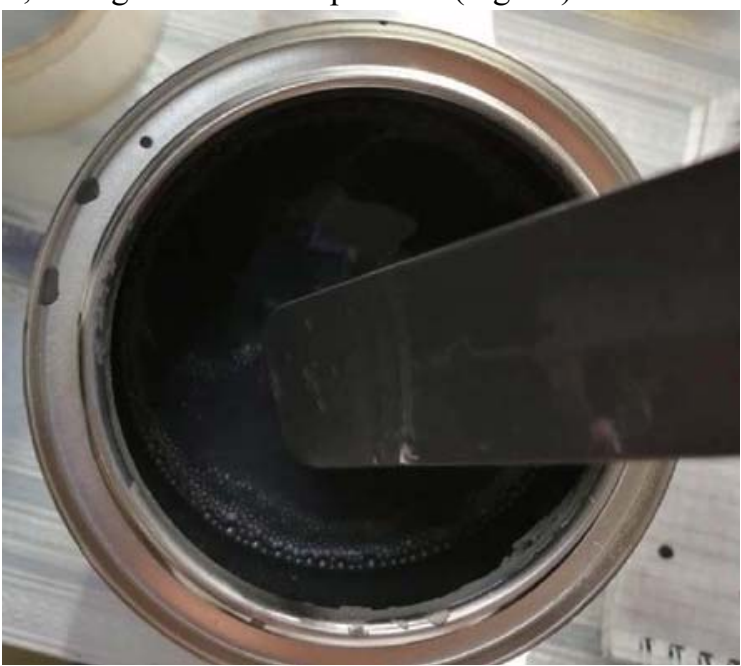

a)

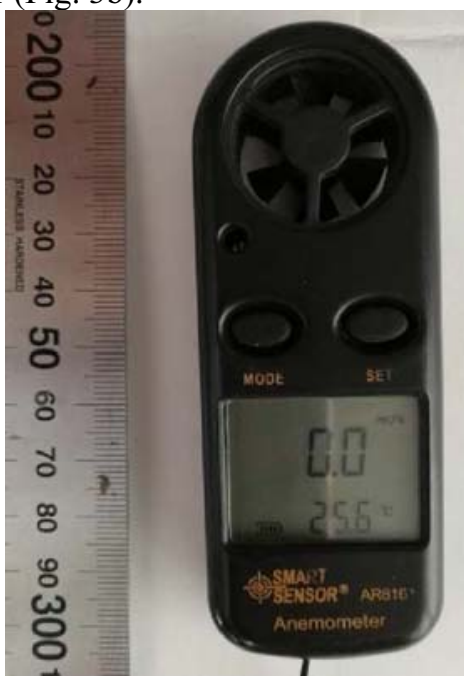

b)

Fig. 3. (a) anti-friction coating; (b) aerometer.

A tripod was used to install the hydrometer and pneumatic sprayer. Distance measurements were carried out using a metal ruler GOST 427-75 (Fig. 4). 


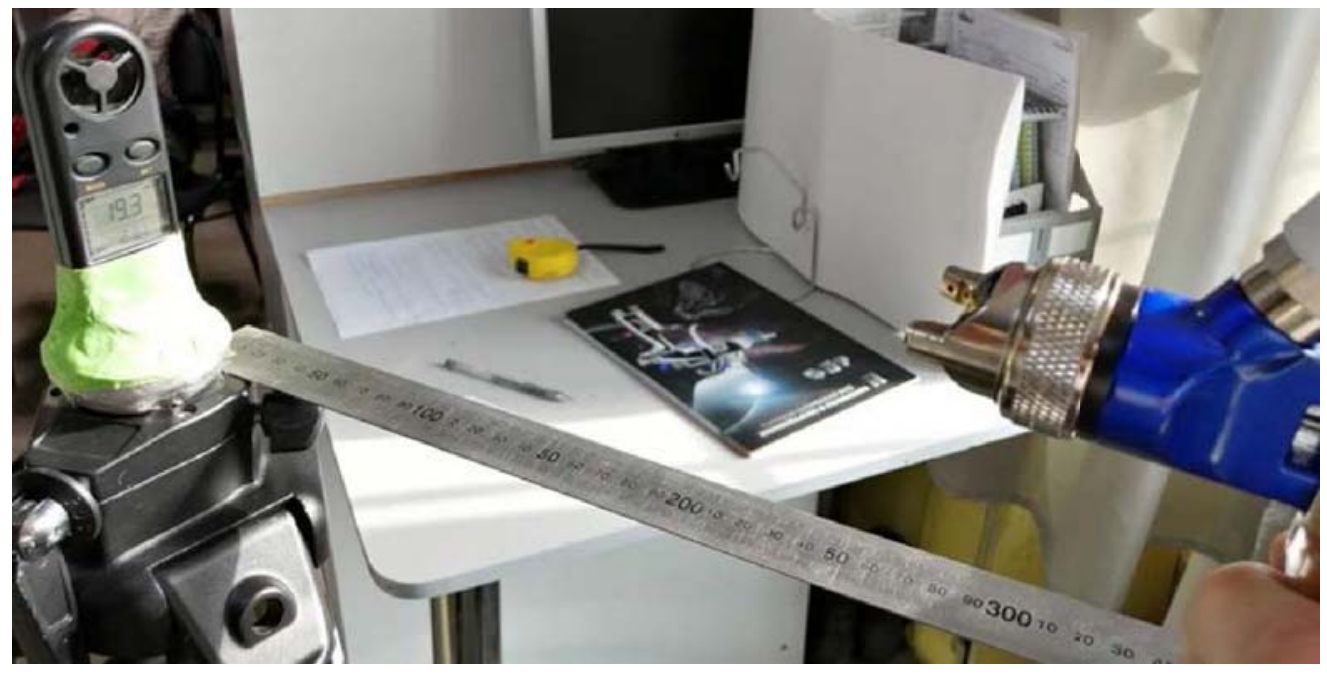

Fig. 4. Air velocity measurement

The optimal parameters of the application of the film anti-friction coating were determined by the torch print (Fig. 5).
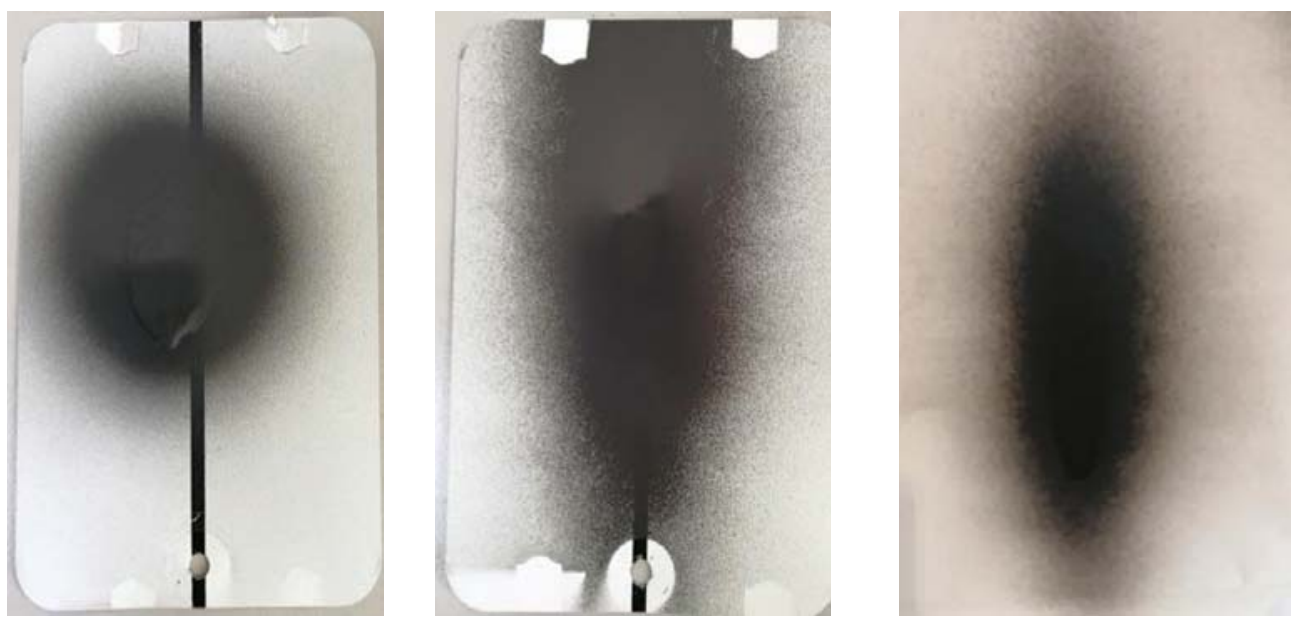

Fig. 5. Torch prints on targets in different modes.

With the correct selection of all parameters, the torch print should be a clear, highly elongated oval of a uniformly applied film coating (possibly with a slight blurring of the edges). Its sides are even, without any protrusions and depressions, and the applied material is evenly distributed over the entire area of the spot.

In the course of the experiments, a functional diagram of the application of an antifriction film coating was obtained. (Fig. 6). 


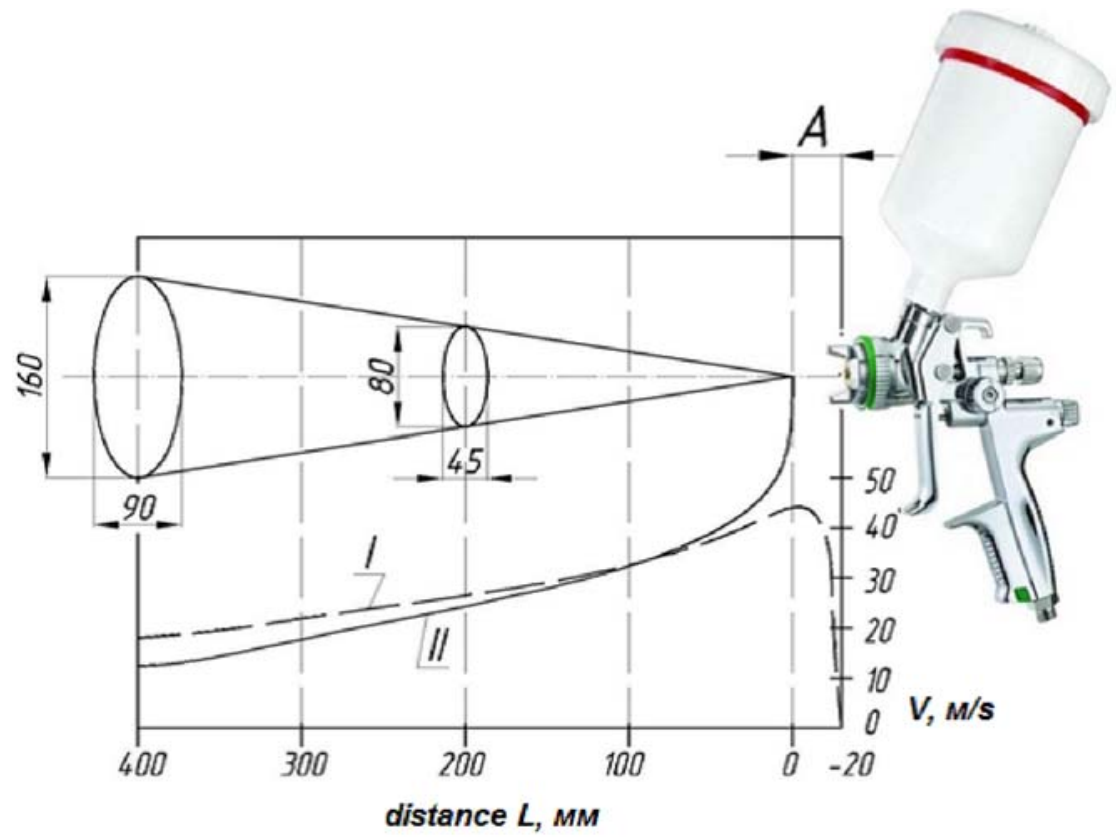

Fig. 6. Functional diagram of the application of an anti-friction film coating:

I - air velocity; II - particle velocity of anti-friction coating;

A - zone of "torch" formation and reaching the maximum speed of the sprayed coating

\section{Conclusions}

The material presented above allows us to draw the following conclusions:

-the application of thin film coatings is a promising method for creating modified friction surfaces;

-to obtain the required tribological properties of modified friction surfaces, it is necessary to know the technological modes of applying thin film coatings;

-the optimal distance for the formation of film anti-friction coatings is $180-200 \mathrm{~mm}$;

-the air velocity in this case is $24-28 \mathrm{~m} / \mathrm{s}$;

-at a distance of $200 \mathrm{~mm}$, the torch print was $80 \mathrm{~mm}$ x $45 \mathrm{~mm}$.

\section{References}

1. I.N. Karp and V.G. Nazarenko Ecotechnology and resource conservation 6, 24, Moscow, (2007)

2. Y.S. Borisov, Y.A. Kharlamov, S.L. Sidorenko, E.N. Ardatovskaya, Thermal Powder Coatings.Directory, Kiev: Science, (1987)

3. S.N. Soloviev, L.P. Klimenko, S.Zh. Budu and E.V. Trofimova Tribotechnology: reference dictionary. Nikolaev. (2003).

4. V.K. Yaroshevich, M.A. Beloretsky Antifriction Metal Powder Coatings, Minsk: Science and technology, (1981)

5. V.Yu. Zamyatin Hardening technologies and coatings 1, 39, Moscow, (2005)

6. I.A. Kurbatov Technology, structure and properties of antifriction materials based on ironcopper system containing graphite. Thesis, Ph.D., Moscow, 1986

7. M.V. Chernets, L.P. Klimenko, M.I. Pashechko and A.A. Nevchas Tribomechanics, 
tribotechnology, tribotechnology, Nikolaev, (2006)

8. A.A. Kutkov Wear-resistant and anti-friction coatings. Moscow, Engineering, (1976)

9. A. Hasuy, O. Morigaki Welding and spraying, Moscow, Engineering (1985)

10. A.V. Gorin, A.Y. Rodichev and M.A. Tokmakova Materials Today: Proceedings 19, 2329 (2019)

11. A.Y. Rodichev, A.V. Gorin and N.V. Tokmakov Materials Science and Engineering 709, 2053, (2020)

12. B.V. Deryagin, N.L. Krotova, V.P. Smilga Adhesion of solids, Moscow: Science, (1973)

13. A.Y. Rodichev, A.V. Sytin, V.V. Barabash, Technological increase of adhesion strength between anti-friction coating and base in bimetal fluid-film bearings, Solid State Phenomena: International Conference on Industrial Engineering, ICIE-2017, 265 284-289, (2017)

14. A.D. Zimon, Adhesion of films and coatings, Moscow: Chemistry, (1977)

15. Y.S. Korobov, Analysis of the properties of gas-thermal coatings: [study guide]: in 2 parts - Yekaterinburg: Publishing house Ural., 2 (2016)

16. A Yu Rodichev, A V Gorin, S V Kolpakova and M A Tokmakova. The influence of surface preparation methods on the adhesionof film antifriction coatings. IOP Conference Series: Materials Science and Engineering 971, 032016, (2020) 